\title{
Development and validation of a triplex real-time PCR for rapid detection and specific identification of $M$. avium sub sp. paratuberculosis in faecal samples
}

\author{
Léonid M. Irenge ${ }^{a}$, Karl Walravens ${ }^{b}$, Marc Govaerts ${ }^{b}$, Jacques Godfroid ${ }^{c}$, \\ Valérie Rosseels ${ }^{\mathrm{d}}$, Kris Huygen ${ }^{\mathrm{d}}$, Jean-Luc Gala ${ }^{\mathrm{a}, \mathrm{e}, *}$ \\ ${ }^{a}$ Defence Laboratories Department, Belgian Armed Forces, Brussels, Belgium \\ ${ }^{\mathrm{b}}$ Veterinary \&' Agrochemical Research Center, Brussels, Belgium \\ ${ }^{\mathrm{c}}$ University of Pretoria, Faculty of Veterinary Science, Department of Veterinary Tropical Diseases, Private Bag X04, Onderstepoort 0110, South Africa \\ d Mycobacterial Immunology, WIV-Pasteur Institute Brussels, Belgium \\ e Centre for Applied Molecular Technologies, Université catholique de Louvain, Brussels, Belgium
}

\section{A R T I C L E I N F O}

\section{Article history:}

Received 5 May 2008

Received in revised form 19 August 2008

Accepted 29 September 2008

\section{Keywords:}

Real-time PCR

Mycobacterium avium subsp. paratubercu-

losis

Faeces

Cattle

Culture

\begin{abstract}
A B S T R A C T
A triplex real-time (TRT-PCR) assay was developed to ensure a rapid and reliable detection of Mycobacterium avium subsp. paratuberculosis (Map) in faecal samples and to allow routine detection of Map in farmed livestock and wildlife species. The TRT-PCR assay was designed using IS900, ISMAP02 and f57 molecular targets. Specificity of TRT-PCR was first confirmed on a panel of control mycobacterial Map and non-Map strains and on faecal samples from Map-negative cows $(n=35)$ and from Map-positive cows $(n=20)$. The TRTPCR assay was compared to direct examination after Ziehl-Neelsen (ZN) staining and to culture on 197 faecal samples collected serially from five calves experimentally exposed to Map over a 3-year period during the sub-clinical phase of the disease. The data showed a good agreement between culture and TRT-PCR (kappa score $=0.63$ ), with the TRT-PCR limit of detection of $2.5 \times 10^{2}$ microorganisms/g of faeces spiked with Map. ZN agreement with TRT-PCR was not good (kappa $=0.02$ ). Sequence analysis of IS900 amplicons from three single IS900 positive samples confirmed the true Map positivity of the samples. Highly specific IS900 amplification suggests therefore that each single IS900 positive sample from experimentally exposed animals was a true Map-positive specimen. In this controlled experimental setting, the TRT-PCT was rapid, specific and displayed a very high sensitivity for Map detection in faecal samples compared to conventional methods.
\end{abstract}

(c) 2008 Elsevier B.V. All rights reserved.

\section{Introduction}

Mycobacterium avium subsp. paratuberculosis (Map) is the etiological agent of paratuberculosis or Johne's disease (JD), a chronic debilitating enteritis with worldwide

\footnotetext{
* Corresponding author at: Centre for Applied Molecular Technologies, UCL/30.46, Clos Chapelle-aux-Champs 30, B-1200 Bruxelles, Belgium. Tel.: +32 276431 65; fax: +32 27643166 .

E-mail address: jean-luc.gala@uclouvain.be (J.-L. Gala).
}

distribution in ruminants and a significant impact on the world economy (Sweeney, 1996; Chacon et al., 2004). Clinical signs of the disease are mostly absent until 2 or more years after the initial infection, which usually occurs shortly after birth. Despite controversies, the assumed implication of Map as one of the causative agents of Crohn's disease in humans (Chacon et al., 2004) further imposes consideration of precautionary control measures in livestock and food sectors.

Although crucial, diagnosis of JD remains difficult. Definitive diagnosis is often made post-mortem on 
relevant biological samples (Godfroid et al., 2005). Specific and sensitive diagnostic methods allowing rapid antemortem detection of Map are critically needed. The detection of Map in faecal samples is among the few direct methods that can be implemented both at the subclinical and clinical stages of disease. Accordingly, direct detection of acid-fast rod bacilli, and culture isolation, currently remain the most common methods for detecting Map in faecal samples, the latter being considered as gold standard for the identification of Map in cattle (Collins et al., 2005). However, faecal culture is slow and poorly sensitive (Bogli-Stuber et al., 2005; Harris and Barletta, 2001 ) whereas direct examination after Ziehl-Neelsen (ZN) staining lacks both specificity and sensitivity (Salem et al., 2005). Such limitations hamper a rapid identification of Map in faeces, delay management decisions to cull infected animals, and allow the pathogen to circulate in herds. Alternatives are given by immunological diagnostic tests. However, their specificity is compromised by close antigenic similarity between Map and other mycobacteria (Collins, 1996; Manning and Collins, 2001). PCR methods have made the rapid identification of Map in clinical samples possible, by reducing detection time (Englund et al., 1999; Fang et al., 2002; Ikonomopoulos et al., 2004; Motiwala et al., 2003, 2004; Rajeev et al., 2005). In most studies, the main DNA target has been the insertion sequence IS900, initially considered to be a Map-specific marker (Green et al., 1989). However, recent reports have challenged the specificity of IS900-based assays due to the discovery of IS900-like sequences in non-Map mycobacteria (Englund et al., 2002; Cousins et al., 1999; Godfroid et al., 2005; Motiwala et al., 2004; Tasara et al., 2005). In order to improve PCR identification of Map, a triplex realtime PCR (TRT-PCR) co-amplifying in the same tube the multi-copy IS900, the single-copy Map-restricted f57 target (Coetsier et al., 2000; Godfroid et al., 2005; Poupart et al., 1993) and the new multi-copy Map-restricted ISMAP02 genetic target (Paustian et al., 2004) was designed. TRT-PCR results were compared on the same faecal samples with methods routinely used for Map identification (i.e. microscopic examination of acid-fast rods after $\mathrm{ZN}$ staining and culture).

\section{Materials and methods}

\subsection{Faeces from calves exposed to Map}

In December 2000, five animals (2-3-week-old calves) were experimentally exposed to Map by the oral route with $10 \mathrm{mg}\left(10^{8} \mathrm{CFU}\right.$ ) of living Map (ATCC 19698) as previously described (Rosseels et al., 2006a). All experiments were approved by the Veterinary and Agrochemical Research Center (VAR) Ethics Committee. Animals were maintained at VAR experimental facilities at Machelen, in accordance with an approved animal care and use protocol. The serological-induced responses and the bacterial excretion in faeces were both monitored during 120 weeks (every week during the first 6 months of the experiment, every 2 weeks after) and Map-specific T-cell immune responses were also analysed during this period (Rosseels et al., 2006a). Between December 2000 and October 2003, 197 faecal samples from these calves were collected and shipped to laboratory for detection and identification of Map. Each sample from the Map exposed calves $(n=197)$ was sonicated during $2 \mathrm{~min}$ at full power $(100 \mathrm{~W})$ using a W-380 sonicator (Heat Systems, Farmingdale, NY) fitted with a cup horn for ice water cooling (Schleig et al., 2005). The sample was subsequently divided into three aliquots, and subjected to microscopic examination after $\mathrm{ZN}$ staining, culture, and TRT-PCR. As positive and negative controls for TRT-PCR specificity, additional faecal samples $(n=35)$ were also obtained from seven calves (3-6-monthold) born from Map culture-negative cows without any history of paratuberculosis and 20 Map culture-positive faecal samples from Map infected cows.

\subsection{Microscopic direct examination}

Faecal smears were fixed on glass slides in an oven at $65^{\circ} \mathrm{C}$, stained by the $\mathrm{ZN}$ method and examined by light microscopy as previously described (Murray et al., 1999).

\subsection{Culture of Map}

Faecal samples ( $1 \mathrm{~g}$ ) were decontaminated in hexadecylpyridium $0.75 \%$ overnight and were centrifuged at $3500 \times g$ for $20 \mathrm{~min}$. Pellets were resuspended in $0.85 \%$ saline and incubated onto four mycobactin J-supplemented HEYM slants (Biomérieux, France). Cultures slopes were incubated at $37^{\circ} \mathrm{C}$ for $2-3$ months.

\subsection{Extraction of Mycobacterium DNA}

Faecal samples ( $1 \mathrm{~g}$ ) were subjected to DNA extraction according to a modified version of a previously described method (Garrido et al., 2000). In brief, $1 \mathrm{~g}$ of faeces was mixed with $20 \mathrm{~mL}$ of SDS 5\% and allowed to sediment for $15 \mathrm{~min}$. The upper aqueous phase was transferred into $15 \mathrm{~mL}$ tubes and washed in PBS three times. The pellet was resuspended in $2.0 \mathrm{~mL}$ of PBS and transferred into a $2 \mathrm{~mL}$ screw cap tube. The suspension was centrifuged at $9600 \times g$ and the supernatant discarded. Bacteria from the pellet were disrupted physically by boiling and freezing, and genomic DNA was extracted with a guanidine isothiocyanate and ammonium acetate solution. The aqueous phase was recovered and extracted twice with an equal volume of chloroform:octanol (24:1). DNA was precipitated with isopropanol and washed with $70 \%$ ethanol. The pellet was air-dried, and DNA was resuspended in $50 \mu \mathrm{L}$ water and quantified by spectroscopy (Nanodrop ND-1000 spectrophotometer, NanoDrop Technologies, Inc., Montchanin, USA).

\subsection{IS900, f57 and ISMAP02 control plasmid}

A plasmid harbouring the three targets was engineered by directed mutagenesis and subsequently used as a control. Briefly, Map DNA was first amplified in two separate PCR reactions using two specific primer pairs, to produce IS900 and f57 overlapping fragments at the $3^{\prime}$ end. The IS900 reverse primer was indeed designed to be complementary to the 557 forward primer. Next, the pooled amplicons were 
amplified using the IS900 forward and $\mathrm{f} 57$ reverse primers, to generate a unique recombinant IS900-f57 target (R1). In a third step, ISMAP02 amplicons were generated to overlap R1 amplicons. A final PCR reaction on pooled R1 and ISMPA02 amplicons was carried out with IS900 forward and ISMAP02 reverse primers, to produce the final IS900-f57-ISMAP02 recombinant target (R2). $\mathrm{R} 2$ amplicons were then cloned in a TOPO-XL vector according to the manufacturer's instructions (Invitrogen, Merelbeke, Belgium).

\section{6. $T R T-P C R$}

Primers and probes were designed from f57 sequence (accession number no. X70277) and ISMAP02 (accession number no. AF445436), using the Primer Express software (version 1.5, PE Applied Biosystems, Foster City, CA, USA). The resulting primer pair candidates and the probe were tested in silico using the GenBank to confirm Map specificity.

Primers and probes from IS900 sequence (accession no. AJ250018) were designed manually in the Map-specific part of IS900, after alignment with all known IS900-like sequences. IS900 primers and probes were selected in Map-specific parts of the IS900 (Table 1). Primers and probes were purchased from Eurogentec (Ougrée, Belgium). TRT-PCR assay was performed using $2.5 \mu \mathrm{L}$ of DNA solution, $12.5 \mu \mathrm{L}$ Universal PCR Master Mix (Applied Biosystems, Foster City, USA), $300 \mathrm{nM}$ of each primer, and $100 \mathrm{nM}$ of each probe, in a total reaction volume of $25 \mu \mathrm{L}$. The reaction was initiated at $50{ }^{\circ} \mathrm{C}$ for $2 \mathrm{~min}$, and $95^{\circ} \mathrm{C}$ for $10 \mathrm{~min}$ followed by 40 cycles of denaturation at $95{ }^{\circ} \mathrm{C}$ for $15 \mathrm{~s}$ and annealing/extension at $60{ }^{\circ} \mathrm{C}$ for $1 \mathrm{~min}$. Each sample was tested in triplicate and data were recorded as cycle threshold $\left(C_{t}\right)$ on a TaqMan 7700 Sequence Detection System (Applied Biosystems), using the analytical software from the same manufacturer. The threshold for a positive fluorescent signal was set arbitrarily at $1 C_{t}$ value $<C_{t}$ of negative controls.

The TRT-PCR was first tested on Map reference strains $(n=3)$ and Map field isolates $(n=22)$ (Supplemental Table S1). Amplicons obtained from these samples were sequenced as previously described (Lecouvet et al., 2004). Sequences obtained were compared with public available sequence databases for similarity-based species identification, using the BLAST (http://www.ncbi.nlm.nih.gov/blast/ Blast.cgi). The specificity of the test was further investigated by performing TRT-PCR analysis on DNA samples from a panel of 48 non-Map mycobacteria, as well as 112 non- mycobacteria species (Supplemental Table S1). TRT-PCR was subsequently performed on DNA extracted from 197 faecal specimens. For each negative sample, PCR inhibition was assessed as previously described (Lecouvet et al., 2004).

In order to compare culture, ZN staining and DNA-based results, a TRT-PCR assay targeting IS900, f57 and ISMAP02 genetic markers was considered unambiguously positive when giving at least two out of three positive signals. Samples with single IS900 positive signal were a priori considered as doubtful until further investigated. For this purpose, the TRT-PCR product of three samples producing a IS900 single positive TRT-PCR signal was cloned in a TOPO-XL vector according to the manufacturer's instructions (Invitrogen, Merelbeke, Belgium) and sequenced as previously described (Lecouvet et al., 2004). Sequences obtained were compared to public available sequence databases for species identification.

\subsubsection{Limit of detection of TRT-PCR}

(a) Serial dilution of control IS900-f57-ISMAP2-plasmid: The control plasmid was serially diluted 1 in 10 to construct a standard curve.

(b) Serial dilution of Map in faecal material: Luminescent Map (ATCC 19698 harbouring plasmid pSMT1 encoding luxAB genes from Vibrio harveyi) was used to spike faeces (Rosseels et al., 2006b). Briefly, Map was grown on 7H9 Middelbrook medium supplemented with OADC, mycobactin J and hygromycin to an O.D. between 0.6 and 0.8. Bacteria were centrifuged and resuspended in PBS. The number of colony forming units (CFU) of Map was checked by plating serial dilutions in PBS on Middlebrook 7H11-OADC agar supplemented with mycobactin J and hygromycin. Petri dishes were incubated at $39^{\circ} \mathrm{C}$ for 8 weeks, before counting colonies visually. Stock concentration was determined to be $1.58 \times 10^{7} \mathrm{CFU} / \mathrm{mL}$. The stock solution was sonicated as described above and serially diluted. Faecal samples were prepared by spiking serial dilutions of $\operatorname{Map}\left(10^{6}, 10^{5}, 10^{4}, 10^{3}, 10^{2}, 10\right.$ and 1 CFU) in $4 \mathrm{~g}$ of faeces from a Map-free donor calf. After overnight stirring, samples were subjected to DNA extraction and subsequent TRT-PCR for Map detection.

\subsection{Statistical analysis}

Statistical analyses were performed using with the NCSS 2004 statistical package release (Kaysville, UT, USA).

Table 1

Primers and probes selected for the triplex PCR identification of M. avium subsp. paratuberculosis.

\begin{tabular}{|c|c|c|}
\hline Primers & Sequence $\left(5^{\prime} \rightarrow 3^{\prime}\right)$ & Location \\
\hline IS900-for & 5'-TGCTGATCGCCTTGCTCA-3' & $1351-1369$ \\
\hline IS900-rev & 5'-GGGCCTGATCGGCGATGAT-3' & $1488-1470$ \\
\hline IS900-probe & 5'-FAM-CCG GGC AGC GGC TGC TTT ATA TTC-3'-BHQ1 & 1375-1398 \\
\hline F57-for & 5'-TTCATCGATACCCAAACTCAGAGA-3' & $428-451$ \\
\hline F57-rev & 5'-GTTCGCCGCTTGAATGGT-3' & $471-453$ \\
\hline F57-probe & 5'YAKIMA YELLOW 5'-TGCCAGCCGCCCACTCGTG-3'-BHQ1 & $495-477$ \\
\hline ISMAP02-for & $5^{\prime}-$ CGC CAG GAA CGC AAA CAT-3' & 946-963 \\
\hline ISMAP02-rev & 5'-GTG CAG GGT CGC TCT GAT G-3' & $1023-1041$ \\
\hline ISMAP02-probe & 5'DragonflyOrange-ACTCCGCATCCAACAACTCACGCTG-3'-BHQ-2 & 946-963 \\
\hline
\end{tabular}


Table 2

Identification of Mycobacterium avium subsp. paratuberculosis in faecal samples: comparison between ZN, culture and triplex real-time PCR.

\begin{tabular}{|c|c|c|c|c|c|c|c|}
\hline Number of faecal samples & $\%$ & IS900 & f57 & ISMAP02 & Final molecular result & Culture & Direct examination after $\mathrm{ZN}$ staining \\
\hline $130^{\mathrm{a}}$ & 51.59 & - & - & - & - & - & - \\
\hline 14 & 5.56 & + & - & - & - & - & - \\
\hline $3^{b}$ & 1.19 & + & & & + & - & - \\
\hline 43 & 17.06 & + & - & - & - & - & + \\
\hline 3 & 1.19 & + & - & + & + & - & - \\
\hline 3 & 1.19 & + & - & + & + & - & + \\
\hline $9^{c}$ & 3.57 & + & - & + & + & + & - \\
\hline 7 & 2.78 & + & + & - & + & - & - \\
\hline 2 & 0.79 & + & + & - & + & - & + \\
\hline 8 & 3.17 & + & + & + & + & - & - \\
\hline 4 & 1.59 & + & + & + & + & - & + \\
\hline $19^{c}$ & 7.54 & + & + & + & + & + & - \\
\hline $7^{c}$ & 2.78 & + & + & + & + & + & + \\
\hline
\end{tabular}

Cohen's kappa correlation coefficient between TRT-PCR and culture on solid medium is 0.63 (good agreement) whereas the correlation between TRT-PCR and direct examination after ZN staining is 0.02 (no correlation at all).

a This number includes the 35 negative control samples.

b These samples were only IS900 positive and initially considered as negative. Confirmation of the amplification of Map IS900 was obtained by cloning and sequencing Taqman amplicons which displayed 100\% identity with Map IS900.

c This number includes the 20 positive control faecal samples (IS900/ISMAP02 positive $(n=6)$ and 14 IS900/ISMAP02/f57 positive ( $n=14$ ) samples).

Agreement between TRT-PCR and culture and between TRT-PCR and direct examination was assessed using the kappa statistics of Cohen.

\section{Results}

\subsection{Assessment of Map-specificity of the TRT-PCR}

The combined use of IS900, ISMAP02 and f57 in a TRTPCR assay produced three concordant positive signals with each of the 25 Map strains tested (three reference strains and 22 field isolates). Further, TRT-PCR results remained negative $\left(C_{\mathrm{t}} 40\right)$ with all non-Map mycobacteria strains and all other bacteria species. Sequence analysis of each amplified target confirmed a $100 \%$ identity with the corresponding target in the Map genome. A series of
Map positive and -negative faecal field samples were also assessed as control of specificity. TRT-PCR results were consistently negative with Map culture-negative samples $(n=35)$ from calves and positive in each sample $(n=20)$ from proved Map culture-positive cows. Positive results included IS900/ISMAP02 positive $(n=6)$ samples or all three positive markers $(n=14)$ (Table 2$)$.

\subsection{Limit of detection: serial dilution of control IS900-f57- ISMAP2-plasmid and Map spiked in faecal material}

The lowest reproducible level of detection in triplicate was 10 plasmid copies. At 10 copies, three exponential curves, one for each insert, were consistently obtained (mean $C_{\mathrm{t}}: 38.1 \pm 0.47$ ), giving a limit of detection of 10 plasmid copies per $25 \mu \mathrm{L}$-reaction for the TRT-PCR assay. The

Table 3

Detection of Mycobacterium avium subsp. paratuberculosis by triplex real-time PCR in faecal samples collected from five calves from December 2000 to September 2003.

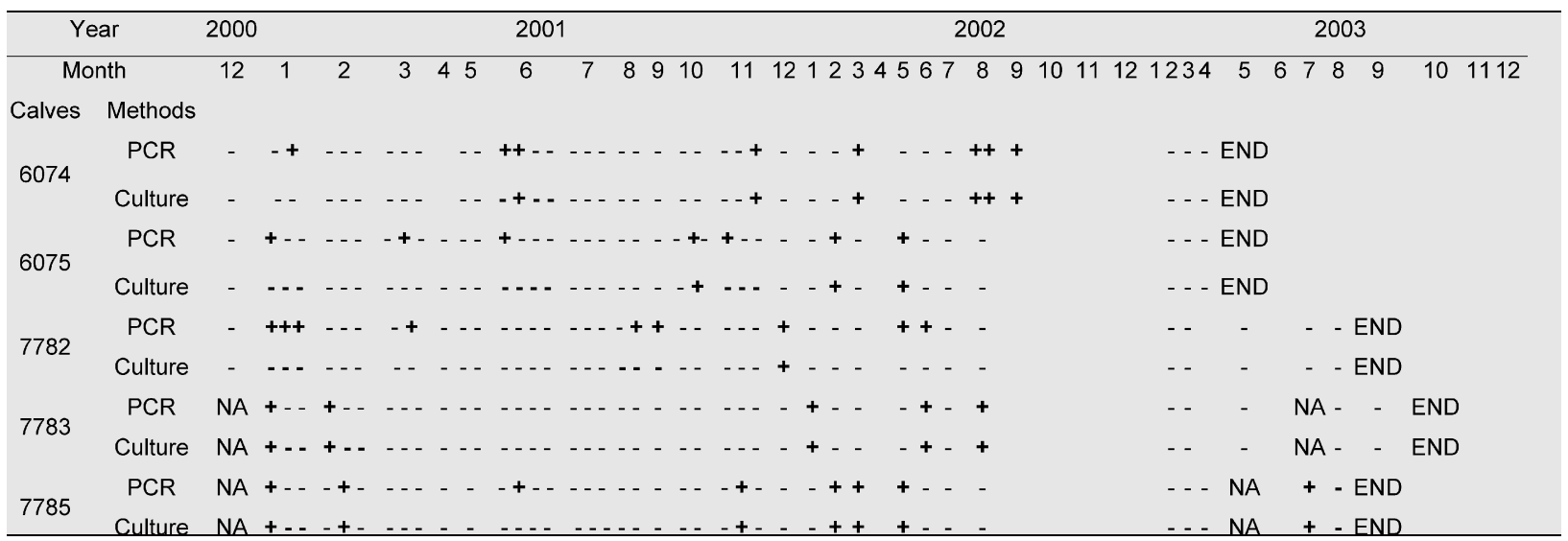

Calves were 2-3 weeks old at time of infection: December 2000. Triplex test result (PCR) and the culture result obtained on a faecal sample collected at a specific day during the month and the year mentioned (+: positive result; -: negative result). Samples collected each month varied from one to maximum three. In the latter case, the samples were collected on different days over that period of time. END means the end of the study and of sample collection. NA: not available. 


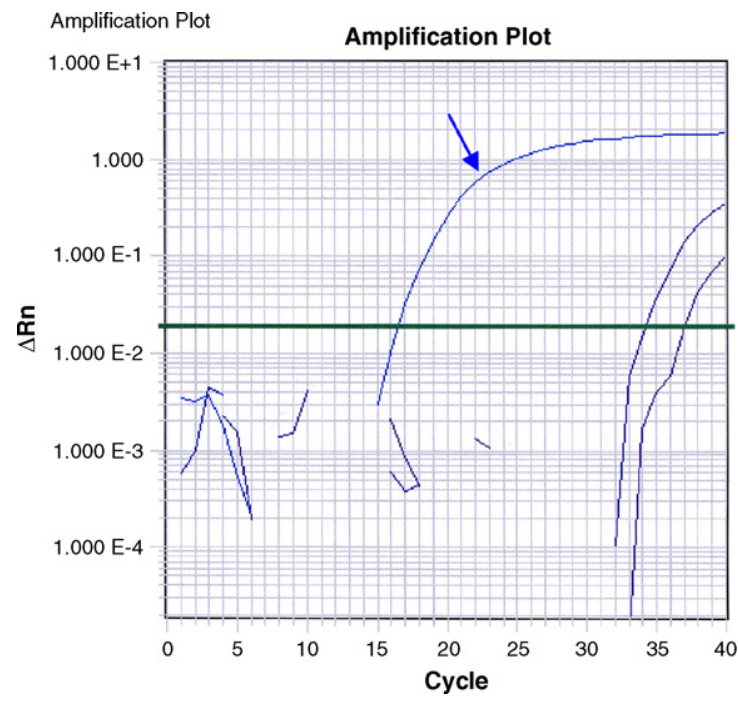

Fig. 1. TRT-PCR from a positive control (arrow) and two IS900-only TRTPCR positive samples.

single-copy gene f57 being the limiting factor for the sensitivity of detection of Map genomic DNA, the detection limit was set at 10 Map per PCR reaction. The dynamic range of amplification was identical for each cloned genetic target, ranging from $10^{2}$ to $10^{7}$ copies. Considering that DNA of Map is extracted from $1 \mathrm{~g}$ of faeces and suspended in a final volume of $50 \mu \mathrm{L}$ from which $2.5 \mu \mathrm{L}$ is used in the TRT-PCR assay, a limit of detection of $\sim 10$ Map gDNA corresponds theoretically, at most, to $200 \mathrm{f57}$ positive-Map/g of stool. This estimation is made assuming a DNA extraction efficiency of $100 \%$.

In our study, data from faecal samples spiked with Map showed a limit of detection equivalent to $12.5 \mathrm{CFU}$ per PCR which corresponds to $250 \mathrm{Map}$ cells/g of faeces. This result corresponds to a Map DNA extraction efficiency of $80 \%$.

\subsection{Comparison between TRT-PCR assay, culture and Ziehl-} Neelsen staining on faecal samples (Tables 2 and 3)

Comparison of ZN staining, culture and TRT-PCR assay in calves experimentally exposed to Map is shown in Table 2. There was no agreement between TRT-PCR and ZN (kappa value: 0.02). The agreement between culture and TRT-PCR was good (kappa value: 0.63). For each of the five calves, positive and negative culture and PCR results were alternatively observed over time, the interval between two samples testing positive being extremely variable (Table 3 ). None of the negative control samples were positive for any of the three molecular targets.

Amplification of only IS900 was found in 60 of 197 of samples (30.5\%), all culture-negative, and 43 of those (71.7\%) were ZN-positive (Fig. 1). This is in agreement with other recently reported data (Meadus et al., 2008). Of note, PCR fragments from three single IS900 positive samples were further cloned, sequenced and proved $100 \%$ identical to IS900.

\section{Discussion}

The control of JD in farmed livestock and in other animal herds is a growing challenge. Control programs are hampered by the lack of sensitive and specific tests able to detect early Map infection. Although PCR-based screening methods performed on (pooled) faecal samples are nowadays offered in some countries, a combination of direct examination of $\mathrm{ZN}$-stained smears, serological methods and culture is still mainly used routinely by veterinary diagnostic laboratories for identifying infected farms (Harris and Barletta, 2001). The rationale for using DNA-based Mapspecific assays on faecal material stems from the expected higher sensitivity and faster performance compared to the culture (Bogli-Stuber et al., 2005; Fang et al., 2002; Huntley et al., 2005; Tasara et al., 2005; Tripathi et al., 2006). Using this experimental Map infection model allowed us to monitor Map excretion over almost 3 years time in the same Map exposed animals and to compare the performance of conventional methods with our DNA-based detection assay on serial faecal samples.

Previous reports have shown that direct examination of faecal smears after ZN staining is not a reliable tool (Salem et al., 2005). This study confirms the lack of sensitivity of the $\mathrm{ZN}$ staining. Moreover, when comparing $\mathrm{ZN}$ results to culture and molecular method, data obtained with this model suggest that ZN staining in Map infected animals may not be an acceptable surrogate of Map faecal shedding as 43 of the 53 (81\%) ZN-positive results were associated with both a negative culture and a negative Map-specific molecular TRT-PCR. Preliminary investigations on these samples show that they contain hsp65 DNA sequences highly conserved among mycobacterial species but with identity to Map $<100 \%$. This is compatible with the presence of non-Map mycobacteria in faeces. Accordingly, $\mathrm{ZN}$-positive samples displaying negative results both in TRT-PCR and culture probably contained non-Map mycobacteria (personal communication). This finding is likely to explain the low specificity of $\mathrm{ZN}$ in our study.

While culture is still considered by most authors as the gold standard for Map identification, it remains a time consuming method which requires up to 16 weeks incubation and displays a low sensitivity (Bogli-Stuber et al., 2005; Harris and Barletta, 2001; Tripathi et al., 2006). In this respect, it has been shown that $30 \%$ of moderately infected sheep with previous negative faecal cultures, disclose gross and microscopic lesions at slaughter (Whitlock et al., 2000). Accordingly, more sensitive methods as real-time PCR should be proposed as gold standards. This report highlights the main diagnostic challenges: the intermittent nature of Map shedding and/ or the lack of sensitivity of culture. Moreover, Map dependency for mycobactin J should be interpreted with caution as some Map strains may grow without mycobactin J (Motiwala et al., 2004; Godfroid et al., 2005). Culture limitations are therefore of particular concern regarding specificity and sensitivity of Map detection in cattle (Sockett et al., 1992). In the absence of a rapid and sensitive assay for the detection of Map infected subclinically affected shedders, as suggested by the results of this study, highly specific PCR assay could be better used 
for the detection of these animals. Regarding single IS900 PCR, many reports have highlighted the lack of specificity of IS900 for Map detection. Previously published IS900 PCR protocols could indeed also amplify IS900-like sequences (Kim et al., 2002; Rajeev et al., 2005; Tasara et al., 2005), which have prompted the use of PCR assays excluding IS900 (Schönenbrücher et al., 2008). Nevertheless, IS900 primers designed according to IS900-like sequences could specifically amplify Map (Kawaji et al., 2007). Likewise, Map-specific IS900 probe and primers were designed in our study according to all known IS900-like elements, giving a $100 \%$ IS900 concordant sequences in three single IS900 PCR positive samples. Consequently, while each IS900 single positive sample is likely to be true Mappositive, it would be time consuming, cumbersome and expensive to confirm the Map-specificity of every IS900only positive sample. ISMAP02 and/or f57 targets are therefore an important adjunct for rapidly confirming the faecal presence of Map. Moreover, the presence of ISMAP02 and/or f57 positive signals is indicative of a higher Map excretion, compared to samples with IS900-only positive signal, as recently suggested (Meadus et al., 2008). Opposingly, the IS900-only positive calves can therefore be considered as low Map shedders. Considering that IS900 can still be found in soils many days after Map removal from the field (Cook and Brilt, 2007), the epidemiological relevance of IS900-only positive shedding requires further investigations. Accordingly, a prospective study focusing on Map transmission in healthy animals exposed to IS900only positive samples could help to assess the epidemiological impact of such results with respect to the risk of Map transmission.

In conclusion, the TRT-PCR presented in this study shows a higher sensitivity compared to culture and to direct examination. Although further validation on a higher number of samples from different herds is mandatory before routine application of the TRT-PCR, results obtained here show that this assay is expected to improve the true detection of Map in faecal samples of subclinically infected animals, and consequently, to support management of JD.

\section{Acknowledgements}

This project was funded by the Walloon Region (grants $981 / 3902$ and $011 / 4853$ ) and by the Department Management of Scientific \& Technological Research of Defence (IRSD-RSTD; Royal High Institute for Defence) supporting research and development (grant MED-03 and MED-08). We thank Michèle Bouyer (IRSD-RSTD), Sabine Jeumont and Jean-François Durant (CTMA), and Yasmine Ghedada (Laboratoire de Biochimie, Hôpital Central de l'Armée, Alger, BP 246 Kouba-Alger) for their outstanding technical contribution to the work.

\section{Appendix A. Supplementary data}

Supplementary data associated with this article can be found, in the online version, at doi:10.1016/j.vetmic.2008.09.087.

\section{References}

Bogli-Stuber, K., Kohler, C., Seitert, G., Glanemann, B., Antognoli, M.C. Salman, M.D., Wittenbrink, M.M., Wittwer, M., Wassenaar, T., Jemmi, T., Bissig-Choisat, B., 2005. Detection of Mycobacterium avium subspecies paratuberculosis in Swiss dairy cattle by real-time PCR and culture: a comparison of the two assays. J. Appl. Microbiol. 99, 587597.

Chacon, O., Bermudez, L.E., Barletta, R.G., 2004. Johne's disease, inflammatory bowel disease, and Mycobacterium paratuberculosis. Annu. Rev. Microbiol. 58, 329-363.

Coetsier, C., Vannuffel, P., Blondeel, N., Denef, J.F., Cocito, C., Gala, J.L., 2000. Duplex PCR for differential identification of Mycobacterium bovis, M. avium, and M. avium subsp. paratuberculosis in formalinfixed paraffin-embedded tissues from cattle. J. Clin. Microbiol. 38, 3048-3054.

Collins, M.T., 1996. Diagnosis of paratuberculosis. Vet. Clin. North Am. Food Anim. Pract. 12, 357-371.

Collins, M.T., Wells, S.J., Petrini, K.R., Collins, J.E., Schultz, R.D., Whitlock, R.H., 2005. Evaluation of five antibody detection tests for diagnosis of bovine paratuberculosis. Clin. Diagn. Lab. Immunol. 12, 685-692.

Cook, K.L., Brilt, S.J., 2007. Optimization of methods for detecting Mycobacterium avium subsp. paratuberculosis in environmental samples using quantitative, real-time PCR. J. Microbiol. Methods 69, 154-160.

Cousins, D.V., Whittington, R., Marsh, I., Masters, A., Evans, R.J., Kluver, P., 1999. Mycobacteria distinct from Mycobacterium avium subsp. paratuberculosis isolated from the faeces of ruminants possess IS900-like sequences detectable by IS900 polymerase chain reaction: implications for diagnosis. Mol. Cell Probes 13, 431-442.

Englund, S., Ballagi-Pordany, A., Bolske, G., Johansson, K.E., 1999. Single PCR and nested PCR with a mimic molecule for detection of Mycobacterium avium subsp. paratuberculosis. Diagn. Microbiol. Infect. Dis. 33, 163-171.

Englund, S., Bolske, G., Johansson, K.E., 2002. An IS900-like sequence found in a Mycobacterium sp. other than Mycobacterium avium subsp. paratuberculosis. FEMS Microbiol. Lett. 209, 267-271.

Fang, Y., Wu, W.H., Pepper, J.L., Larsen, J.L., Marras, S.A., Nelson, E.A., Epperson, W.B., Christopher-Hennings, J., 2002. Comparison of realtime, quantitative PCR with molecular beacons to nested PCR and culture methods for detection of Mycobacterium avium subsp. paratuberculosis in bovine fecal samples. J. Clin. Microbiol. 40, 287-291.

Garrido, J.M., Cortabarria, N., Oguiza, J.A., Aduriz, G., Juste, R.A., 2000. Use of a PCR method on fecal samples for diagnosis of sheep paratuberculosis. Vet. Microbiol. 77, 379-386.

Godfroid, J., Delcorps, C., Irenge, L.M., Walravens, K., Marche, S., Gala, J.L., 2005. Definitive differentiation between single and mixed mycobacterial infections in red deer (Cervus elaphus) by a combination of duplex amplification of p34 and f57 sequences and Hpy188I enzymatic restriction of duplex amplicons. J. Clin. Microbiol. 43, 4640 4648.

Green, E.P., Tizard, M.L., Moss, M.T., Thompson, J., Winterbourne, D.J., McFadden, J.J., Hermon-Taylor, J., 1989. Sequence and characteristics of IS900, an insertion element identified in a human Crohn's disease isolate of Mycobacterium paratuberculosis. Nucleic Acids Res. 17, 9063-9073.

Harris, N.B., Barletta, R.G., 2001. Mycobacterium avium subsp. paratuberculosis in veterinary medicine. Clin. Microbiol. Rev. 14, 489-512.

Huntley, J.F., Whitlock, R.H., Bannantine, J.P., Stabel, J.R., 2005. Comparison of diagnostic detection methods for Mycobacterium avium subsp. paratuberculosis in North American bison. Vet. Pathol. 42, 42-51.

Ikonomopoulos, J., Gazouli, M., Pavlik, I., Bartos, M., Zacharatos, P., Xylouri, E., Papalambros, E., Gorgoulis, V., 2004. Comparative evaluation of PCR assays for the robust molecular detection of Mycobacterium avium subsp. paratuberculosis. J. Microbiol. Methods 56, 315-321.

Kawaji, S., Taylor, D.L., Mori, Y., Whittington, R.J., 2007. Detection of Mycobacterium avium subsp. paratuberculosis in ovine faeces by direct quantitative PCR has similar or greater sensitivity compared to radiometric culture. Vet. Microbiol. 125, 36-48.

Kim, S.G., Shin, S.J., Jacobson, R.H., Miller, L.J., Harpending, P.R., Stehman, S.M., Rossiter, C.A., Lein, D.A., 2002. Development and application of quantitative polymerase chain reaction assay based on the ABI 7700 system (TaqMan) for detection and quantification of Mycobacterium avium subsp. paratuberculosis. J. Vet. Diagn. Invest. 14, 126-131.

Lecouvet, F., Irenge, L., Vandercam, B., Nzeusseu, A., Hamels, S., Gala, J.L., 2004. The etiologic diagnosis of infectious discitis is improved by amplification-based DNA analysis. Arthritis Rheum. 50, 2985-2994.

Manning, E.J., Collins, M.T., 2001. Mycobacterium avium subsp. paratuberculosis: pathogen, pathogenesis and diagnosis. Rev. Sci. Tech. 20 $133-150$ 
Meadus, W.J., Gill, C.O., Duff, P., Badoni, M., Saucier, L., 2008. Prevalence on beef carcasses of Mycobacterium avium subsp. paratuberculosis DNA. Int. J. Food Microbiol. 124, 291-294.

Motiwala, A.S., Amonsin, A., Strother, M., Manning, E.J., Kapur, V., Sreevatsan, S., 2004. Molecular epidemiology of Mycobacterium avium subsp. paratuberculosis isolates recovered from wild animal species. J. Clin. Microbiol. 42, 1703-1712.

Motiwala, A.S., Strother, M., Amonsin, A., Byrum, B., Naser, S.A., Stabel, J.R., Shulaw, W.P., Bannantine, J.P., Kapur, V., Sreevatsan, S., 2003. Molecular epidemiology of Mycobacterium avium subsp. paratuberculosis: evidence for limited strain diversity, strain sharing, and identification of unique targets for diagnosis. J. Clin. Microbiol. 41, 2015-2026.

Murray, P.R., Baron, E.J., Pfaller, M.A., Tenover, F.C., Yolken, R.H., 1999. Manual of Clinical Microbiology, 7th edition. ASM Press, p. 1678.

Paustian, M.L., Amonsin, A., Kapur, V., Bannantine, J.P., 2004. Characterization of novel coding sequences specific to Mycobacterium avium subsp. paratuberculosis: implications for diagnosis of Johne's disease. J. Clin. Microbiol. 42, 2675-2681.

Poupart, P., Coene, M., Van Heuverswyn, H., Cocito, C., 1993. Preparation of a specific RNA probe for detection of Mycobacterium paratuberculosis and diagnosis of Johne's disease. J. Clin. Microbiol. 31, 1601-1605.

Rajeev, S., Zhang, Y., Sreevatsan, S., Motiwala, A.S., Byrum, B., 2005. Evaluation of multiple genomic targets for identification and confirmation of Mycobacterium avium subsp. paratuberculosis isolates using real-time PCR. Vet. Microbiol. 105, 215-221.

Rosseels, V., Marche, S., Roupie, V., Govaerts, M., Godfroid, J., Walravens, K., Huygen, K., 2006a. Members of the 30- to 32-kilodalton mycolyl transferase family (Ag85) from culture filtrate of Mycobacterium avium subsp. paratuberculosis are immunodominant Th1-type antigens recognized early upon infection in mice and cattle. Infect. Immun. $74,202-212$.
Rosseels, V., Roupie, V., Zinniel, D., Barletta, R.G., Huygen, K., $2006 b$. Development of luminescent Mycobacterium avium subsp. paratuberculosis for rapid screening of vaccine candidates in mice. Infect. Immun. 74, 3684-3686.

Salem, M., Zeid, A.A., Hassan, D., El-Sayed, A., Zschoeck, M., 2005. Studies on Johne's disease in Egyptian cattle. J. Vet. Med. B: Infect. Dis. Vet. Public Health 52, 134-137.

Schleig P.M., Buergelt, C.D., Davis, J.K., Williams, E., Monif, G.R., Davidson, M.K., 2005. Attachment of Mycobacterium avium subspecies paratuberculosis to bovine intestinal organ cultures: method development and strain differences. Vet. Microbiol. 108, 271-279.

Schönenbrücher, H., Abdulmawjood, A., Failing, K., Bülte, M., 2008. New triplex real-time PCR assay for detection of Mycobacterium avium subsp. paratuberculosis in bovine feces. Appl. Environ. Microbiol. 74, 2751-2758.

Sockett, D.C., Carr, D.J., Richards, W.D., Collins, M.T., 1992. A repository of specimens for comparison of diagnostic testing procedures for bovine paratuberculosis. J. Vet. Diagn. Invest. 4, 188-191.

Sweeney, R.W., 1996. Transmission of paratuberculosis. Vet. Clin. North Am. Food Anim. Pract. 12, 305-312.

Tasara, T., Hoelzle, L.E., Stephan, R., 2005. Development and evaluation of a Mycobacterium avium subspecies paratuberculosis (MAP) specific multiplex PCR assay. Int. J. Food Microbiol. 104, 279-287.

Tripathi, B.N., Periasamy, S., Paliwal, O.P., Singh, N., 2006. Comparison of IS900 tissue PCR, bacterial culture, johnin and serological tests for diagnosis of naturally occurring paratuberculosis in goats. Vet. Microbiol. 116, 129-137.

Whitlock, R.H., Wells, S.J., Sweeney, R.W., Van Tiem, J., 2000. ELISA and fecal culture for paratuberculosis (Johne's disease): sensitivity and specificity of each method. Vet. Microbiol. 77, 387-398. 